\title{
Teleologia: relação entre ciência e religião e sua influência sobre o ensino de evolução biológica
}

Valdir Lamim-Guedes lamimguedes@gmail.com 0000-0002-5021-4176 Doutorando em Educação - USP Docente na Pós-graduação em

Educação Ambiental para a

Sustentabilidade do Centro

Universitário Senac - Santo Amaro,

São Paulo, Brasil.

\section{RESUMO}

Uma explicação teleológica está vinculada à ideia de finalidade, muitas vezes adotando termos como propósito, objetivo e função, e tem desempenhado um papel central ao longo da história das ciências da vida. Dada a extensa presença destas explicações na nossa cultura, estas se tornam um ponto de atenção muito importante para professores, sobretudo daqueles que se dedicam ao ensino de biologia, com destaque para a evolução biológica. Neste texto, buscamos apresentar uma visão histórica das explicações teleológicas nas ciências da vida, a adoção destas por movimentos criacionistas e, por fim, os impactos sobre o ensino de evolução biológica.

PALAVRAS-CHAVE: Educação científica. Criacionismo. Darwin. 


\section{TELEOLOGIA COMO EXPLICAÇÃO PRIMEIRA PARA O MUNDO NATURAL}

Uma explicação teológica ${ }^{1}$ é aquela em que alguma propriedade, processo ou entidade é justificada apelando-se a um resultado ou consequência particular que algumas destas podem trazer. Explicações teológicas têm desempenhado um papel central ao longo da história das ciências da vida, assim como, uma compreensão exata destas é muito importante para professores, sobretudo aqueles que se dedicam ao ensino de biologia, com especial atenção à evolução biológica. Isto porque muitos docentes usam explicações teleológicas ao abordar a existência de alguma característica apelando para o valor adaptativo ${ }^{2}$ (LENNOX; KAMPOURAKIS, 2013).

Uma explicação teleológica, em ciências biológicas, é caracterizada pela

referência às noções de 'propósito', 'função', 'objetivo', e, de modo geral, pode ser reconhecida por expressões como 'papel de', 'contribui para' além de outras semanticamente equivalentes. Trata-se, assim de um modo de explicação que se caracteriza pelo conceito de finalidade (CARMO; NUNESNETO; EL-HANI, 2012, p. 28).

A origem da teleologia data da Grécia antiga, com Platão (427 a.C.-347 a.C.) e Aristóteles (385 a.C.-323 a.C.). Platão argumentava que se um objeto natural tem uma propriedade devido a um agente inteligente, então ele a tem, porque é a melhor que pode ter. Esta percepção influenciou a visão sobre a teleologia como uma ação divina (Demiurgo, que é o deus criador para os Platônicos). Aristóteles também usou a teleologia como explicação para o mundo natural, mas sem referência a alguma ação inteligente ${ }^{3}$, em vez disto, conferiu explicações teleológicas para justificar a constituição de partes de seres vivos, incluindo os humanos, ou seja, que certas características existem para o sucesso de seu possuidor (Conforme LENNOX; KAMPOURAKIS, 2013; extensamente tratado por SOLINAS, 2015).

As influências platônicas e aristotélicas persistiram ao longo da idade média, tanto na tradição judaico-cristã, como na árabe. Durante a revolução científica, sobretudo no século XVII, esta influência permaneceu, por exemplo, nas obras de René Descartes (1596-1650), John Ray (1627-1705) e Robert Boyle (1627-1691), sendo o primeiro alinhado entre os aristotélicos e os outros dois platônicos. Boyle e Ray defendem a validade de explicações teleológicas em estudos sobre seres vivos, sobretudo, justificando órgãos complexos como evidência de um designer racional. Por outro lado, Descartes criticava o uso de causas finais na filosofia natural, chegando a afirmar que deveríamos banir completamente da nossa filosofia a busca por causas finais (LENNOX; KAMPOURAKIS, 2013).

Nos séculos XVIII e XIX, destacam-se dois nomes William Paley (1743-1805), um platônico, e Georges Cuvier (1769-1832), aristotélico (LENNOX; KAMPOURAKIS, 2013). Cuvier usou a paleontologia, classificação e anatomia animais como base para uma teleologia aristotélica. De acordo com Cuvier, um organismo não pode existir se não forem atendidas todas as condições necessárias para a existência. Tais condições dizem respeito apenas ao próprio organismo, sem considerar a influência ambiental. O programa de pesquisa de Cuvier tem como consequência a impossibilidade, prática e conceitual, da evolução das espécies, com a impossibilidade de fases intermediárias das estruturas complexas.

A Teologia Natural de Paley é bastante conhecida pela metáfora do relógio: 
Mas suponhamos que eu tivesse encontrado um relógio no chão e que devesse investigar como ele foi parar ali (...). Alguém deve ter feito o relógio: deve ter existido (...) um artífice (...) que o fez com a finalidade à qual nós achamos que ele de fato corresponde; alguém que compreendeu sua construção e projetou seu uso (...). Todas as indicações de perspicácia, todas as manifestações de projeto presentes no relógio existem nas obras da natureza; com a diferença, a favor da natureza, de elas serem maiores ou mais numerosas, e isso num grau que ultrapassa todos os cálculos (PALEY apud LENNOX, 2009, s.p.).

Considera-se que a Teologia Natural de Paley, como uma 'religião da natureza', era uma forma de estudar o mundo se aproximando do criador, através da compreensão de sua obra. "Os exemplos de perfeição, que podia ser vista desde a estrutura das flores até a arquitetura de esqueletos, documentavam as altas habilidades intelectuais do responsável pela criação do mundo" (BIZZO, 2007, p. 354). Embora não estivesse imune às críticas teológicas e políticas na GrãBretanha, esse modo de pensamento cresceu dramaticamente no começo do século XIX e se tornou a principal doutrina daqueles que eram favoráveis à estabilidade social e à preservação do status quo político; resumindo, tornou-se a ideologia das classes dominantes britânicas e dos acadêmicos de Cambridge em particular, onde Darwin teve boa parte da sua formação superior (BROWNE, 2011). "Para muita gente da época, a imagem de Deus não era a de um monarca absoluto, que fazia milagres e soltava raios, mas a de um guardião cuidadoso que via todas as coisas e as arranjava para que funcionassem com eficiência" (BROWNE, 2007, p. 23-24). Apesar da relevância de Paley para o pensamento da época, o seu pensamento foi substituído gradativamente por um mais sofisticado, que envolvia acadêmicos religiosos que pesquisam diversos aspectos do mundo natural de forma que "estudar a natureza era estudar a obra do Senhor (...). De certo modo, a ciência era a religião" (BROWNE, 2011, p. 196).

\section{TELEOLOGIA E DARWIN}

Darwin (1809-1882) teve sua formação acadêmica entre uma visão mais cética em Edimburgo, no curso de medicina (que ele não concluiu), e uma visão criacionista baseada no literalismo bíblico de Cambrigde (em fase de transição para uma visão metafórica da Bíblia). A posição darwiniana, inicialmente semelhante à de seu pai e de seu avô - o também famoso evolucionista Erasmus Darwin (17311802) -, era de que o criador seria "uma força externa que criou o mundo e permitiu que ele funcionasse segundo leis naturais intrínsecas" (BROWNE, 2011, p. 197). Segundo Bizzo (2007, p. 361), antes mesmo da publicação do A Origem das Espécies (1859), Darwin já tinha rompido com a teologia natural de Paley, sendo que as criaturas não eram mais "perfeitamente ajustadas a seu meio, mas apenas soluções precárias e provisórias em busca de novos nichos para garantir sua sobrevivência". De fato, as teorias de Darwin sobre a mudança geológica, para a qual a viagem pelos Andes ${ }^{4}$ foi determinante (BIZZO, 2002), de herança intergeracional e, por fim, a seleção natural, tinham como obstáculo epistemológico a adaptação perfeita.

Em Origem das Espécies Darwin forneceu uma explicação para a origem da adaptação que não ocorria diretamente nem à intervenção de uma 
caracteres adquiridos, a principal contribuição de Darwin para a compreensão da adaptação foi propor o mecanismo da seleção natural como principal causa da evolução da vida (CHEDIAK, 2008, p. 13-14).

O botânico americano Asa Gray (1810-1888), professor da Universidade de Harvard, era um dos principais defensores da teoria darwinista nos Estados Unidos, tendo mediado a publicação oficial do Origem, defendendo os interesses editoriais de Darwin. Apesar de seu empenho na defesa da teoria darwinista, ele achava que esta deveria ser adequada para acomodar a papel de Deus no mundo natural, pois não acreditava que o mecanismo de seleção natural era capaz, por si só, para dar origem a tantos organismos. Gray "propôs que Deus criara variações boas e úteis, e que a seleção natural depois preservava em uma população" (MILES, 2001, s.p.).

Assim como Thomas Henry Huxley (1825-1895), "O Buldogue de Darwin", vários naturalistas percebiam a natureza sem a necessidade de um criador no século XIX. O famoso debate realizado em 30 de junho de 1960 entre Huxley e o Bispo Samuel Wilberforce (1805-1873) demonstra as tensões entre as teorias evolutivas e as tentativas de relacioná-las a leituras literais da bíblia (INTERNATIONAL DARWIN DAY FOUNDATION, 2017). Este era o caso de Fritz Müller (1821-1897), alemão que viveu no Brasil e que trocava cartas com Darwin, que afirmou em seu livro Für Darwin (Para Darwin):

assim lanço tranquilamente este grão de areia na balança, contra a 'montanha de preconceito sob a qual este assunto está enterrado', despreocupado se os sacerdotes de uma ciência absoluta me juntem aos sonhadores ou às crianças no conhecimento das leis da natureza (MÜLLER, 2009 [1864], p. 24).

Para Ribeiro et al. (2010, p. 8), o fato do acaso desempenhar um papel essencial no processo evolutivo pode ser considerado como uma das conclusões mais revolucionárias da teoria darwinista, "retirando do imaginário humano a ideia de que somos seres especiais, de alguma forma protegidos pelos desígnios de uma deidade".

Mayr (2005) propõe cinco categorias para dividir os fenômenos teleológicos: processos teleomáticos ${ }^{5}$; processos teleonômicos ${ }^{6}$; comportamento com propósito; características adaptativas e teleologia cósmica, sendo os quatro primeiros fenômenos estritamente materiais e que não atendem a uma meta futura, muito menos a algo sobrenatural. Neste sentido, tratamos neste texto, basicamente, a relação entre a teleologia cósmica e a evolução. Sobre isto, Mayr (2005, p. 81), afirma que:

Decerto é a seleção natural um processo de otimização, mas não tem meta definida, e, considerando o número de restrições e a frequência de eventos aleatórios, seria por demais equivocado chamá-la de teleológica. Nenhum melhoramento em adaptação tampouco constitui um processo teleológico, porque a decisão quanto a uma mudança evolutiva qualificar-se como contribuição para a adaptação é estritamente post hoc.

A percepção do processo evolutivo como uma forma de bricolagem vai de encontro com o trecho acima. Segundo Meyer e El-Hani (2005, p. 131): “A evolução é frequentemente considerada um processo que se assemelha mais à atividade de bricolagem do que de engenharia, na qual, as peças são feitas para realizar funções específicas". 


\section{PERMANÊNCIA DA TELEOLOGIA NA CONTEMPORANEIDADE E O MOVIMENTO CRIACIONISTA DO DESIGN INTELIGENTE}

A permanência da teleologia deve-se ao fato das causas finais serem "muito mais plausíveis e agradáveis para o leigo que o aparentemente tão acidental e oportunista processo de seleção natural. Por essa razão, a crença em causas finais teve influência muito maior fora da biologia do que dentro dela" (MAYR, 2005, p. 59). Atualmente, o movimento criacionista do Design Inteligente tem adotado a teleologia como principal explicação para os fatos do mundo natural.

O Design Inteligente é uma versão moderna, suposta científica, de criacionismo. Este movimento

tem retomado as teses de São Tomás de Aquino (1225-1274), colocando suas conhecidas provas da existência de Deus, que lastreavam o que ele chamara de Teologia Natural, em contextos modernos, focalizando a biologia molecular. O finalismo aristotélico, que entendia as formas das partes dos seres vivos como expressão de suas finalidades, foi revigorado nas teses de Tomás de Aquino ("tomismo") e é entendido como plenamente válido por este movimento. Nada pode ser atribuído ao acaso, mas as suas causas finais (segundo Aristóteles) ou a Deus (segundo Tomás de Aquino) (BIZZO; GOUW; RIOS, 2013, p. 114).

É interessante notar o esforço que alguns escritores fazem para mostrar que não existem grandes problemas em associar um criador aos processos naturais. 0 matemático inglês John Lennox, no livro Por que a ciência não consegue enterrar deus (2009), retira da obra de biólogos como Stephen Jay Gould (1941-2002) e Richard Dawkins menções que não atacam diretamente o Design. Por exemplo, ele abre o capítulo "Biosfera projetada?" com a frase de Gould "nenhuma força vital impulsiona mudanças evolucionárias. E o que quer que pensemos de Deus, sua existência não é claramente visível em produtos da natureza"; e cita a definição de Dawkins para biologia como "o estudo de coisas complicadas que dão a impressão de ter sido projetadas com um propósito" (2009, s.p.). Lennox (2009, s.p.) comenta sobre uma suposta indefinição destes dois autores:

temos diante de nós uma situação bastante estranha: De um lado, há quase instintiva e avassaladora tentação de inferir da existência e da natureza das informações biológicas que elas têm uma origem inteligente. De outro lado, algumas das pessoas que admitem que a tentação é forte opõem-se forte resistência de nenhum projetista; processos evolucionários não dirigidos, aleatórios podem ser, e foram, a causa de tudo.

Usar uma frase de Gould é algo aceitável, dada à elegância de sua escrita, no entanto não devemos enganar isto com alguma dúvida deste cientista sobre a ação divina na criação de espécies! Mais grave, neste caso, é indicar que Dawkins tivesse alguma afeição pelo Design, este que é um cientista inglês famoso por seus argumentos bastante ácidos sobre o criacionismo. Um argumento, minimamente, respeitoso de nossa parte é dizer que: nada como uma operação quase cirúrgica para pinçar estas frases de seus contextos. No entanto, Lennox enverada pela lógica - como matemático - para mostrar a retórica em afirmações de Dawkins. Inclusive, ele sugere precaução a seus leitores, colocando em termos de "tomar cuidado" com a retórica de Dawkins.

Lennox poderia seguir outro caminho em sua argumentação, baseado na coexistência de diferentes percepções, sendo este o mote de outro livro que critica 
o biólogo inglês: O Delírio de Dawkins: uma resposta ao fundamentalismo ateísta de Richard Dawkins (MACGRATH; MACGRATH, 2007), no entanto, ele prefere a lógica e ignorar todas as evidências fósseis, anatômicas, ecológicas e genéticas que sustentam a seleção natural como mecanismo da evolução biológica.

O esforço de Lennox não é único, muito menos isolado. Repetidamente nos deparamos com ações de lobby criacionista. Bizzo, Gouw e Rios (2013), comentam que, apesar de 2009 ser o aniversário de 200 anos de nascimento de Darwin e 150 anos da publicação do A origem das Espécies, a Organização das Nações Unidas para a Educação, a Ciência e a Cultura (UNESCO) dedicou este ano a Galileu Galilei, devido aos 400 anos de uso de um instrumento já vendido em Paris, pelo menos, desde o ano anterior. Talvez esta ação seja resultado da pressão deste lobby. Leite (2009) cita a adoção do material didático intitulado Ciências - Projeto Inteligente por uma escola confessional de São Paulo, enquanto Lamim-Guedes (2014), denuncia a retórica de um pastor evangélico ao atacar um geneticista que fez um vídeo criticando a visão preconceituosa deste religioso. Ainda neste contexto, visões distorcidas da biografia de Darwin são usadas para difamá-lo, por exemplo, indicando-o como um "amador" e que nunca teve uma educação formal em biologia (LAMIM-GUEDES, COSTA JUNIOR, 2014), como no trecho a seguir,

Ele tinha apenas interesse amadorístico em coisas relacionadas com a natureza e os seres vivos. (...) A hipótese de Darwin não se baseou em qualquer descoberta ou experimento científico. No decorrer do tempo, entretanto, ele a tornou em uma pretensiosa teoria com o apoio e encorajamento que recebeu de famosos biólogos materialistas da época (YAHYA, 2007, p. 20).

Para Wilson (2008, p. 186-187),

\begin{abstract}
as provas do Design Inteligente consistem apenas em um argumento fundamentado na falta de provas. Sua lógica é simples: os biólogos ainda não explicaram de que modo sistemas complexos, tais como o olho humano, ou os cílios bacterianos giratórios, podem ter evoluído por si mesmos; portanto, uma inteligência mais elevada deve ter guiado a evolução. Infelizmente ${ }^{7}$, não há nenhuma evidência positiva para a existência desse Design Inteligente. Nenhuma prova concreta chegou a ser apresentada a fim de ser testada. Nenhuma teoria foi sugerida, nem sequer imaginada, para explicar a transferência de uma força sobrenatural para uma realidade orgânica. E é por isto que os cientistas de respeito, os que estão à frente das pesquisas originais, concordam, unanimemente, que a teoria do Design Inteligente não satisfaz os requisitos necessários para ser considerada ciência.
\end{abstract}

Alguns já sugeriram que os cientistas participaram de uma conspiração para a busca do Design Inteligente. Não existe tal conspiração, em absoluto. Existe apenas o consenso entre os especialistas de que essa hipótese não possui nenhuma das qualidades que definem a ciência.

Responder a estes ataques tem ocupado muitos cientistas, o que nos faz questionar se devemos gastar estes esforços. Segundo William R. Rose, "ao defenderem dos criacionistas o campo científico, os biólogos evolucionistas estão defendendo toda a ciência" (2000, p. 237). Um argumento relacionado a isto é a influência política da religião no país, por exemplo, com o crescente aumento do número de deputados religiosos eleitos (MEDEIROS; FONSECA, 2016). 


\section{ENSINO DE EVOLUÇÃO BIOLÓGICA: A PRESENÇA DO PENSAMENTO TELEOLÓGICO}

Explicações teleológicas são comuns em livros textos da área de biologia, por exemplo, ao citar que um peixe macho é mais colorido para atrair as fêmeas, em uma contextualização da seleção natural na ecologia evolutiva de vertebrados, a linguagem soa suspeitosamente teleológica (LENNOX; KAMPOURAKIS, 2013). Isto acaba por impactar a percepção que os alunos têm da teoria evolutiva e do mundo natural de forma geral.

De acordo com Santos e Bizzo (2000 apud RIBEIRO et al. 2010, p. 8), conforme ocorre o ensino da teoria darwinista da evolução, as crenças religiosas vão sendo desafiadas e, através de elaborações cognitivas, os conteúdos vão sendo elaborados e reorganizados de forma a manter as crenças religiosas.

Bizzo, Gouw e Rios (2013) aplicaram um questionário a jovens brasileiros sobre a relação entre ciência e religião. Eles encontraram indícios de que a "nova geração de estudantes não demonstra adesão total aos dogmas religiosos, pelo menos no que tange sua extensão ao campo científico e mesmo pessoal" (p. 117), e, em relação aos argumentos de introdução do criacionismo na educação básica, vinculados a um aumento dos evangélicos no país, os autores afirmam que "nossa juventude demonstra entender que a ciência não pode ser vista como um simples sistema de verdades e dogmas, e que a religião não pode impedir o desenvolvimento de nossa capacidade de observar e interpretar o mundo" ( $p$. 118).

Ribeiro et al. (2010) estudaram as concepções teleológicas entre estudantes universitários ingressantes no curso de Ciências Biológicas de uma universidade pública brasileira. Partindo do conceito de obstáculo epistemológico de Bachelard (1996) e das categorias de teleologia propostas por Mayr (2005), os autores pediram que os alunos analisassem uma projeção composta pela fotografia de um beija-flor próximo a uma flor de corola tubular e com a frase "torna-se cada vez mais evidente que o organismo desenvolve estruturas especiais para promover suas capacidades de evoluir e que essas estruturas expandem enormemente o escopo do processo evolutivo" (CAMPBELL, 1985 apud MAYR, 2005), citada por Mayr como exemplo da persistência do pensamento teleológico em publicações recentes. Estes autores concluíram que poucos alunos tinham uma visão adequada do processo de evolução. Muitos alunos afirmaram que a adaptação é o objetivo do processo evolutivo, por exemplo, no trecho: "A tendência natural é a adaptação... A adaptação é o objetivo" (p. 5); ou então, a ideia de melhoria: "A evolução nos seres vivos é um processo demorado que é desencadeado para a melhor adaptação desses seres ao meio ambiente" (p. 6). O conjunto de citações apresentadas pelos autores não indica a presença de um Designer inteligente, contudo, a visão teleológica aristotélica aparece repetidamente ou, pelo menos, um descuido dos alunos na hora de explicar suas concepções relacionadas ao processo evolutivo. Galli e Meinardi (2015), também encontraram resultados semelhantes na Argentina. Estes autores consideram que entender o impacto de obstáculos na compreensão da evolução biológica por seleção natural é útil para o planejamento de estratégias didáticas que permitam uma compreensão mais adequada deste fenômeno.

Wounters (2013) afirma que uma parte substancial da formação de um biólogo consiste em aprender a pensar sobre função, adaptação e evolução de 
forma que diferem da abordagem cotidiana. Um aspecto bastante interessante nesta visão é que os alunos aprendem isto de forma implícita, por exemplo, através da resolução de problemas em livros didáticos, analisando problemas reais ou sob a supervisão de professores e/ou tutores em atividades realizadas em laboratório ou em campo. Desta forma, uma interpretação não intuitiva é desenvolvida de forma gradual e imperceptível.

Várias pesquisas, copiladas por Lennox e Kampourakis (2013), sobre os usos de teleologia, tanto em crianças como em adultos, indicam que não é errado dizer que os seres humanos têm o coração para bombear sangue ou que as águias têm asas para voar, enquanto a pessoa está consciente de que essas características não existem porque eles foram projetados intencionalmente a fim de cumprir algum propósito final, mas porque elas são favorecidas pela seleção natural que confere uma vantagem e contribuir para a sobrevivência e reprodução de seus portadores.

Carmo, Nunes-Neto e El-Hani (2012), de forma semelhante, afirmam no texto É legítimo explicar em termos teleológicos na biologia? que:

(...) defendemos a legitimidade de explicar em termos teleológicos na biologia, desde que tal explicação seja limitada à compreensão de fenômenos em seres vivos que são dirigidos para objetivos, como os processos fisiológicos e o comportamento. É inadequado explicar teleologicamente outros fenômenos biológicos, como a evolução.

Ferreira (2003) faz um comentário importante que demonstra parte da complexidade em se tratar alguns assuntos em aulas de biologia de forma adequada com a evolução biológica:

Diante do modo de reprodução de uma espécie, das proporções de uma estrutura ou do padrão de uma migração, ninguém honestamente se pergunta: 'Como as mutações nos genes dessa característica vieram a se estabelecer por seleção?' A pergunta efetiva seria 'Em que esta característica serve à sobrevivência, qual sua função?' (FERREIRA, 2003, p. 190).

Segundo Ribeiro et al. (2010, p. 9), ao considerarmos que a palavra função é usada em muitos sentidos, "seu emprego deve ser cuidadoso, de forma a evitar-se a interpretação incorreta de que os papéis biológicos de uma estrutura ou de um órgão não têm uma origem evolutiva". Assim, os professores devem perceber até que ponto seus alunos compreendem afirmações supostamente teleológicas como resultado de processos naturais.

\section{DIÁLOGO ENTRE CONHECIMENTOS?}

A partir dos desafios relacionados à teleologia citados acima, podemos pensar em uma relação entre religião e ciência menos conflituosa? Juliette Nouel-Rénier, no livro de divulgação científica Foi assim que o homem descobriu que o macaco é nosso primo (2009), comenta

O importante é que esses cientistas [paleoantropólogos, biólogos e primatólogos] se ponham de acordo com o essencial: o homem, o macaco e todos os outros seres vivos são o resultado da evolução, e esta é inteiramente fruto do acaso e da seleção natural. 
Nada na observação da natureza - dos fósseis aos genes - faz pensar num programa qualquer: de um ponto de vista científico, o aparecimento do homem não é o resultado de nenhum plano predeterminado. Essa hipótese foi enunciada pela primeira vez por Darwin, comprovada em várias outras ocasiões e é o fundamento de todas as ciências da vida (p. 58).

A seguir ela aborda os ataques religiosos à teoria de evolução biológica, afirmando inclusive que até os religiosos evoluem, para introduzir o conceito de Design inteligente (como uma nova roupagem do criacionismo). Segundo a autora, é possível ser religioso e acreditar na teoria da evolução, "simplesmente porque estas duas afirmações - Deus criou o mundo, e o homem e os grandes símios têm um ancestral comum - não se situam no mesmo plano. A primeira é religiosa e supõe a fé; a segunda é científica e requer provas" (p. 61, ênfase no original). Nas páginas seguintes, já concluindo o livro, Nouel-Rénier ressalta que várias questões em aberto sobre a origem e evolução humanas serão respondidas por novos fósseis, evidências arqueológicas e genéticas. A forma como ela apresentou as informações, baseadas na racionalidade científica, dificilmente permitiria um diálogo entre áreas de conhecimento distintas.

Edward O. Wilson, no livro A Criação: como salvar a vida na Terra (2008), tenta abrir uma via para o diálogo com um interlocutor imaginário (pastor evangélico) em prol da conservação da biodiversidade.

\footnotetext{
Para o senhor, a glória de uma divindade invisível; para mim, a glória do universo por fim revelado. Para o senhor, a crença em um Deus que se fez para salvar a humanidade; para mim, a crença no fogo que Prometeu arrebatou para libertar os homens. O senhor encontrou sua verdade final; eu ainda estou buscando a minha. Eu posso estar errado, ou o senhor pode estar errado. Talvez nós dois estejamos parcialmente certos (p. 12).
}

Com isto, ele não propõe que os dois concordem em relação às suas visões de mundo, mas que reúnam esforços para um objetivo comum, o que abre uma via de diálogo que pode ter desdobramentos práticos importantes, como o apoio à criação de Unidades de Conservação. Porém, fica claro no texto a discordância em relação ao processo evolutivo: "Eu gostaria de poder pensar de outra maneira, mas não vejo esperança alguma de chegarmos a uma solução conciliatória sobre a ideia do Design Inteligente" (p. 186). Isto significa que, apesar da possibilidade de unir esforços e da posição respeitosa adotada no texto, há questões que ficarão em aberto. Para a tentativa de buscar uma forma de diálogo entre áreas de conhecimento, Wilson apresenta uma possibilidade, que é interessante e permite uma coexistência menos conflituosa.

Parte do problema neste diálogo está em que a religião (incluindo aqui o Design Inteligente) e a Ciência tomam para si a posição de únicas detentoras da verdade. O posicionamento da Ciência em relação a outras formas de conhecimento é chamado de pensamento abissal pelo português Boaventura de Souza Santos (2007). Este autor parte desta percepção para falar de um pensamento pós-abissal, que permite a ocorrência de uma ecologia de saberes. usando uma epistemologia do Sul. Ele confronta a monocultura da ciência moderna com uma ecologia de saberes, na medida em que se funda no reconhecimento da pluralidade de conhecimentos heterogêneos (sendo um deles a ciência moderna) e em interações sustentáveis e dinâmicas entre eles 
Para Santos (em entrevista a CARNEIRO; KREFTA; FOLGADO, 2014, p. 332), "a ecologia de saberes é um conceito que visa promover o diálogo entre vários saberes que podem ser considerados úteis para o avanço das lutas sociais pelos que nelas intervêm", sendo um "processo coletivo de produção de conhecimentos que visa reforçar as lutas pela emancipação social” (p. 332). Neste processo devese saber ouvir, pois esta construção de conhecimento é coletiva, como em um mutirão indígena.

A ecologia de saberes interessa-nos ser citada aqui, porque consideramos que uma forma de aproximar religião e ciência parte da visão de que são formas distintas de conhecimento, que podem interagir. Aliado a isto, dentro de uma perspectiva de Epistemologias do Sul (SANTOS, 2007), ao tratar de religião não estamos falando apenas das três grandes religiões monoteístas, mas também às cosmovisões indígenas e afrodescendentes, no caso brasileiro. Assim, uma pluralidade de visões de mundo, partindo de formas de conhecimento distintas, podem coexistir, mas de forma complementar.

Partindo desta visão de diálogo entre distintas formas de conhecimento, a escola pode abrigá-las, por exemplo, sendo abordadas durante as aulas. Porém, dado o cenário atual, que ainda se tem nas escolas uma abordagem muito fragmentada de saberes, acreditamos que seja mais produtivo e gerando menos conflitos, abordar nas aulas de ciências a teoria da evolução biológica como explicação adotada para entender o nosso mundo, sem a necessidade de uma teleologia cósmica, enquanto na aula de religião ou filosofia, pode-se tratar das várias visões religiosas para a constituição do mundo (não apenas a cristã). Assim, no ambiente escolar teremos uma multiplicidade de visões, de forma que nenhum tipo de conhecimento tenha o status de verdade.

Mesmo considerando a necessidade de termos uma ecologia de saberes, como ressaltado acima, desconhecemos no cenário nacional iniciativas que poderíamos destacar como exemplar. Por outro lado, diversas escolas confessionais adotam sistemas de ensino que buscam em seus materiais tratar da evolução biológica e do criacionismo juntos. Este é o caso de muitas escolas Adventistas, por exemplo, a obra Biologia volume 10 (FÁVARO; MACHADO; ROMANGNOLI, 2013), apresenta trechos como no box "razões para crer", no qual é descrito o pescoço da girafa e outros fatos sobre este animal: "essas e outras características, como as fantásticas condições de nascimento dos filhotes, apontam para um produto do acaso ou para um design inteligente?" (p. 3) e indicam como leitura complementar um texto, que faz afirmações como: "Para aumentar ainda mais a maravilha, temos o nascimento de uma girafa que certifica o argumento do design inteligente" (HOFLAND, s/d.) De forma geral, o texto deste livro didático busca apresentar uma suposta visão neutra, baseada na vantagem de ter contato com mais de uma teoria. Contudo, o que vemos é a construção de um discurso com vários artifícios linguísticos como "há cientistas que acreditam" ou "se a hipótese evolucionista estivesse correta" (p. 9), que trazem dúvidas ao aspecto teórico discutido. Além disto, o conhecimento científico não é apresentado como dinâmico, sendo naturais as modificações nas teorias, refutações, corroborações e quebras de paradigma. Somado a isto, são apresentadas "falhas" da teoria da evolução biológica, com o designer inteligente sendo apresentado como teoria alternativa, mas não é comentada nenhuma falha 
ou limitação desta. Neste sentido, é um debate que critica uma teoria e enaltece outra, fugindo de qualquer perspectiva de diálogo minimamente equilibrado.

De forma semelhante, Santos e Baptista (2009, s.p.), analisando livros didáticos escritos segundo a Pedagogia Adventista, comentam que nos trechos analisados sobre a origem da vida é dada a ênfase ao criacionismo em detrimento da origem química da vida, ocorrendo tentativas de convencer o leitor de uma suposta superioridade epistemológica dos argumentos criacionistas. Os livros didáticos analisados por estes autores apresentam "abordagem de maneira híbrida sobre a Origem da vida, com pouco aprofundamento nos argumentos científicos e contendo incorreções científicas" e, concluem que os que os

\begin{abstract}
Mesmo em escolas de tradição religiosa, que tenham como objetivo central a construção de uma educação cristã nos indivíduos, não é produtivo a incorporação nos livros didáticos de ciências de conteúdos de natureza bíblica. Os resultados dessa incorporação serão sempre prejudiciais, tanto para uma educação científica quanto para uma educação religiosa que se pretenda com qualidade, pois, sendo os conhecimentos apresentados de maneira híbrida, os estudantes não conseguirão perceber uma clara demarcação do discurso científico e nem do discurso bíblico. O livro didático de ciência deve servir como instrumento de apoio aos educadores e educandos, no entendimento daquilo que é consensual na cultura científica atual (SANTOS; BAPTISTA, 2009, s.p.).
\end{abstract}

Falcão e Trigo (2016, 133), analisando as percepções de alunos sobre os temas origem do universo e surgimento da vida encontraram um "esforço de estudantes para harmonizar, a partir de sua base cultural, explicações religiosas e científicas no que se refere às questões da origem do universo e da vida". Porém, estas autoras fazem uma ressalva,

\footnotetext{
não podemos afirmar que rejeições às explicações científicas possam ser atribuídas exclusivamente às influências de crenças religiosas dos estudantes porque também verificamos que professores disseram ser limitado o tempo dedicado aos temas investigados, o que nos permite considerar a possibilidade de haver falhas no ensino de tais temas.
}

Em relação ao ensino de ciências, é importante não apresentar as informações científicas em tom de verdades incontestáveis, assim como, apresentar o processo de investigação científica, como indicado por Delicado (2008) para os museus de ciências. O objetivo da compreensão pública da investigação científica (em contraposição à compreensão pública da ciência) é "mostrar ao público o processo de investigação, os procedimentos, a competitividade, a aspiração à objetividade, apesar da dependência de julgamentos subjetivos, e a natureza provisória dos resultados" (FARMELO, 2004, p. 9 apud DELICADO, 2008, p. 82). De forma que afirmar "dizem cientistas" ou "comprovado cientificamente" não deveria colocar um ponto final em uma discussão, mas abrir mais frentes de debate, como a discussão sobre as metodologias usadas nos estudos científicos ou os contextos em que foram produzidos. Este posicionamento crítico é muito importante para uma visão não idealizada da ciência, assim como para negar a validade de explicações teleológicas cósmicas (MAYR, 2005). 


\section{CONSIDERAÇÕES FINAIS}

Neste texto, partimos de uma visão histórica da adoção de explicações teleológicas (causas finais) nas ciências da vida, já que estas têm desempenhado um papel central ao longo da história das ciências da vida. Uma compreensão exata destas é muito importante para professores, sobretudo daqueles que se dedicam ao ensino de biologia, com especial atenção à evolução biológica.

Darwin rompeu com esta forma de ver o mundo natural ao propor a relação entre herança intergeracional e seleção natural, que influenciou fortemente as ciências naturais. Apesar da influência darwiniana, as causas finais ainda influenciam muito o imaginário das pessoas e têm sido adotadas por movimentos criacionistas como principal explicação para fatos do mundo natural. Desta forma, conforme William R. Rose, "ao defenderem dos criacionistas o campo científico, os biólogos evolucionistas estão defendendo toda a ciência" (2000, p. 237).

Explicações teleológicas são comuns em livros textos da área de biologia, por exemplo, ao citar que um peixe macho é mais colorido para atrair as fêmeas, sendo que a linguagem soa suspeitosamente teleológica (LENNOX; KAMPOURAKIS, 2013). Isto pode impactar a percepção que os alunos têm do mundo natural, desta forma, os professores devem ter cuidado no seu discurso para evitar afirmações teleológicas. Aliado a isto, consideramos que não é adequado o ensino concomitante entre a teoria evolutiva e visões religiosas durante as aulas de ciências e biologia, como defendido por muitos grupos criacionistas. Por outro lado, acreditamos que a escola deve adotar uma visão plural de mundo, incluindo visões religiosas monoteístas, indígenas e afrodescendentes, sendo o locus adequado para esta abordagem as aulas de ciências humanas, como sociologia, filosofia ou religião.

Em relação ao ensino de ciências, defendemos o esforço para apresentar o conhecimento científico como um produto humano, estando sujeito a reformulações e evitando uma a visão de que é acabado ou estanque. Uma forma de reforçar a dinâmica científica é dando destaque a uma compreensão pública da investigação que se preocupa com uma perspectiva processual da ciência, com seus procedimentos, busca pela objetividade, mas que depende de subjetividades, e a característica de ter resultados provisórios (DELICADO, 2008).

Dois pontos deste estudo demonstram potenciais para o desenvolvimento de novas pesquisas: o discurso adotado em livros didáticos, sobretudo confessionais, de forma a possibilitar uma análise crítica destes materiais; desenvolvimento de ações educativas que reforcem uma visão de ciência menos estereotipada, destacando os procedimentos utilizados para as descobertas científicas. Desta forma, podemos ter um posicionamento crítico que é muito importante, tanto para uma visão não idealizada da ciência, como para negar a validade de explicações teleológicas. 


\title{
Teleology: relationship between science and religion and its influence on teaching of biological evolution
}

\begin{abstract}
A teleological explanation is linked to the idea of finality, often adopting terms such as purpose, goal and function, and have played a central role throughout the history of life sciences. Given the extensive presence of these explanations in our culture, these become a very important point of attention for teachers, especially those dedicated to teaching biology, with emphasis on biological evolution. In this text, we seek to present a historical view of teleological explanations in the life sciences, their adoption by creationist movements and, finally, the impacts on the teaching of biological evolution.
\end{abstract}

KEYWORDS: Science education. Creationism. Darwin. 
1 Segundo o Dicionário de Filosofia de Sérgio Biagi Gregório (s.d.): Teleologia. (Do grego telos, fim, e logos, discurso) Ciência ou estudo da finalidade. Quando é sinônimo de finalismo, o termo se opõe a mecanismo. Segundo Kant, o uso da teleologia é justificado no estudo do ser vivo ou da obra de arte, pois nos dois casos, a explicação teleológica, que considera as partes em virtude do todo, é a única esclarecedora (1). Teleológico. 1. Concernente a teleologia. 2. Fil. Diz-se de explicação, argumento etc. que faz a relação entre um fato e sua causa final (2). Teleologia. A suposição de que existe uma finalidade ou propósito nos acontecimentos não humanos. Crença, elaborada por Aristóteles, de que a natureza tem um propósito (3). Teleologia. Explicação dos fenômenos pelo propósito a que servem e não por meio de causas postuladas (4). Fonte: (1) DUROZOI, G.: ROUSSEL, A. Dicionário de Filosofia. Tradução de Marina Appenzeller. Campinas, SP: Papirus, 1993. (2) DICIONÁRIO ENCICLOPÉDICO ILUSTRADO LAROUSSE. São Paulo: Larousse, 2007. (3) HUXLEY, Sir Julian e outros. O Pensamento: Filosofia, Religião, Moral. Publicações Europa-Americana, 1970 (Glossário). (4) LEVENE, Lesley. Penso, Logo Existo: Tudo o que Você Precisa Saber sobre Filosofia. Tradução de Debora Fleck. Rio de Janeiro: Casa da Palavra, 2013.

2 Isto fica claro quando usam a expressão "tal característica evolui para ...".

3 "em Aristóteles as concepções teleológicas não envolvem agentes externos à natureza e a analogia entre natureza e artífice é tão somente isto, uma analogia" (FERREIRA, 2003, p. 184).

4 "Com o que tinha diante de seus olhos, Darwin contemplava a planície do conhecimento humano a partir do telhado da América. A teoria do mundo tinha de ser repensada e, com ela, as ideias a respeito da origem das espécies em nosso planeta" (BIZZO, 2002, p. 148).

5 Processos teleomáticos são aqueles relacionados ao fato dos objetos do mundo físico terem a capacidade de mudar de estado, respeitando leis naturais, atendendo às forças ou condições externas de forma automática. Um exemplo é o decaimento radioativo.

6 "Processo ou comportamento teleonômico é aquele que deve sua orientação por uma meta à influência de um programa evoluído" (MAYR, 2005, p. 69), sendo baseado em informações genéticas. Processos como migração, corte e ontogenia são exemplos de processo ou comportamento teleonômico.

7 Esta afirmação do autor deve-se ao fato de que nesta obra, ele busca o diálogo com um pastor evangélico. Neste sentido, se houvesse alguma prova do Design Inteligente a tentativa de unir esforços seria mais simples, devido à concordância de opiniões e visões de mundo.

\section{REFERÊNCIAS}

BACHELARD, G. A Formação do Espírito Científico: contribuição para uma psicanálise do conhecimento. Rio de Janeiro: Contraponto, 1996. 
BIZZO, N. Darwin - do telhado dos Andes à Teoria da Evolução. São Paulo:

Editora Odysseus, 2002.

BIZZO, N. Darwin e o fim da adaptação perfeita dos seres vivos: a superação da visão teológica de Paley e o princípio da divergência. Filosofia e História da Biologia, v. 2, p. 351-367, 2007.

BIZZO, N.; GOUW, A. M. S.; RIOS, H. M. Posturas de jovens brasileiros em relação à evolução biológica. In: BIZZO, N.; PELLEGRINI, G. Os Jovens e a Ciência. Curitiba: CRV, 2013. pp. 113-120.

BROWNE, J. “A Origem das Espécies” de Darwin: uma biografia. Rio de Janeiro: Jorge Zahar, 2007.

BROWNE, J. Charles Darwin: viajando. São Paulo: Aracati; Unesp, 2011.

CAMPBELL, J. Na organization interpretation of evolution. In: DEPEW, D.; WEBER, B.H. Evolution at a crossroads. Cambridge: MIT, 1985. pp. 133-167.

CARMO, R. S.; NUNES-NETO, N. F.; EL-HANI, C. N. É legítimo explicar em termos teleológicos na biologia? Revista da Biologia, v. 9, n. 2, p. 28-34, 2012.

CARNEIRO, F. F.; KREFTA, N. M.; FOLGADO, C. A. R. A Práxis da Ecologia de Saberes: entrevista de Boaventura de Souza Santos. Tempus, Brasília, v. 8, n. 2, p. 331-338, 2014.

CHEDIAK, K. Filosofia da Biologia. Rio de Janeiro: Jorge Zahar, 2008.

DARWIN, C. The origin of species by means of natural selection. Londres: John Murray, 1859.

DELICADO, A. Microscópios, batas brancas e tubos de ensaio: Representações da ciência nas exposições científicas. Revista Crítica de Ciências Sociais, v. 83, p. 7989, 2008.

FALCÃO, E. B. M.; TRIGO, E. D. Origem do universo, diversidade das espécies e fenômenos da natureza: ciência e religião no ensino médio. Revista Brasileira de Ensino de Ciência e Tecnologia, v. 8, n. 1, 2015. 
FARMELO, G. Only Connect: Linking the Public with Current Scientific Research. In CHITTENDEN, D. et al. (Orgs.). Creating Connections: Museums and the Public Understanding of Research. Walnut Creek: Altamira Press, 2004. pp. 1-26.

FÁVARO, C. L. J.; MACHADO, M.F.; ROMANGNOLI, W.O. Biologia. 2 ed. Tatuí - SP: Casa Publicadora Brasileira, 2013. (Sistema inter@tivo de ensino: 3o. No, livro 10).

FERREIRA, M. A. A teleologia na Biologia contemporânea. Scientiae Studia, v. 1, p. $183-193,2003$.

GALLI, L. G.; MEINARDI, E. Obstáculos para el aprendizaje del modelo de evolución por selección natural, em estudiantes de escuela secundaria de Argentina. Ciência e Educação, Bauru, v. 21, n. 1, p. 101-122, 2015.

GOULD, S. J. Os Dentes da Galinha. Rio de Janeiro: Paz e Terra, 1996.

GREGÓRIO, S. B. Dicionário de Filosofia. Disponível em <https://sites.google.com/view/sbgdicionariodefilosofia/>. Acesso em 21 jun.2017.

HOFLAND, L. Girafas: animais que se destacam na multidão. Creationism, s. d. Disponível em < http://www.creationism.org/portuguese/giraffes pt.htm>. Acesso em 21 jun.2017.

INTERNATIONAL DARWIN DAY FOUNDATION. The Huxley Wilberforce Debate. 2017. Disponível em <http://darwinday.org/educate/oxforddebate/>. Acesso em 21 jun.2017.

LAMIM-GUEDES, V. Alfabetização científica: muito além do entender como se faz ciência. Revista do Edicc, v. 2, p. 117-127, 2014.

LAMIM-GUEDES, V.; COSTA JUNIOR, J. Visões sobre a vida e obra de Darwin: conhecendo Charles e sua 'ideia perigosa'. ComCiência (UNICAMP), v. 155, 2014

LEITE, M. Darwin. São Paulo: Publifolha, 2009.

LENNOX, J. C. Por que a ciência não consegue enterrar deus. São Paulo: Mundo Cristão, 2009. 
LENNOX, J. G.; KAMPOURAKIS, K. Biological Teleology: the need for history. In: KAMPOURAKIS, K. (ed.) Philosophy of Biology: a Companion to Educators. Dordrecht: Springer, 2013. pp 421-454.

MACGRATH, A.; MACGRATH, J. O Delírio de Dawkins: uma resposta ao fundamentalismo ateísta de Richard Dawkins. São Paulo: Mundo Cristão, 2007.

MAYR, E. Biologia, Ciência Única: Reflexões sobre a autonomia de uma disciplina científica. São Paulo: Companhia das Letras, 2005.

MEDEIROS, É.; FONSECA, B. As bancadas da Câmara. Agência Pública, 18 fev.2016. Disponível em <http://apublica.org/2016/02/truco-as-bancadas-dacamara/>. Acesso em 21 jun.2017.

MEYER, D.; EL-HANI, C. Evolução: o sentido da biologia. São Paulo: Editora da UNESP, 2005.

MILES, S. J. Charles Darwin and Asa Gray discuss teleology and desing.

Perspectives on Science and Christian Faith, 53: 196-201, set. 2001. Disponível em <http://www.asa3.org/ASA/PSCF/2001/PSCF9-01Miles.htm|\#10>. Acesso em 21 jan.2017.

MÜLLER, F. Para Darwin. Florianópolis: editora da UFSC, 2009 [1864].

NOUEL-RÉNIER, J. Foi assim que o homem descobriu que o macaco é nosso primo. São Paulo: Companhia das Letras, 2009.

RIBEIRO, M. G. L.; LARENTIS, A. L.; CALDAS L. A.; KAERCHER, L. E.; HERBST, M. H.; ALMEIDA, R. V.; CABRAL, L. M. Teoria Darwinista da Evolução: identificação de concepções teleológicas entre estudantes do primeiro período de graduação em Ciências Biológicas. In: III Anais do Encontro Nacional de Ensino de Biologia, IV Encontro Regional de Ensino de Biologia da Regional 5, V Congresso Iberoamericano de Educación en Ciencias Experimentales, 2010, Fortaleza - CE.

ROSE, W. R. O Espectro de Darwin: a teoria da evolução e suas implicações no mundo moderno. Rio de Janeiro: Jorge Zahar, 2000.

SANTOS, B. S. Para Além do Pensamento Abissal: das linhas globais a uma ecologia de saberes. Novos Estudos, v. 79, nov. 2007. 
epistemológico. Anais do VII Encontro Nacional de Pesquisas em Educação em Ciências, Florianópolis, novembro de 2009.

SANTOS, S. C.; BIZZO, N. O ensino e a aprendizagem no quotidiano da sala de aula. Coletânea do VII Encontro Perspectivas do Ensino de Biologia. São Paulo, 2000.

SOLINAS, M. From Aristotle's Teleology to Darwin's Genealogy: the stamp of inutility. Nova York: Macmillan, 2015.

WILSON, E. O. A Criação: como salvar a vida na Terra. São Paulo: Companhia das Letras, 2008.

WOUNTERS, A. G. Biology's Functional Perspective: roles, advantages and organization. In: KAMPOURAKIS, K. (ed.) Philosophy of Biology: a Companion to Educators. Dordrecht: Springer, 2013. pp 421-454.

YAHYA, H. O engano do evolucionismo. Brasília: Sociedade Criacionista Brasileira, 2007.

Recebido: 2017-06-28

Aprovado: 2018-05-28

DOI: $10.3895 /$ rbect.v11n3.6071

Como citar: LAMIN-GUEDES, V. Teleologia: relação entre ciência e religião e sua influência sobre o ensino de evolução biológica. Revista Brasileira de Ensino de Ciência e Tecnologia, v. 11, n. 3, 2018. Disponível em:

<https://periodicos.utfpr.edu.br/rbect/article/view/6071>. Acesso em: xxx. Correspondência: Valdir Lamim-Guedes - lamimguedes@gmail.com Direito autoral: Este artigo está licenciado sob os termos da Licença Creative Commons-Atribuição 4.0 Internacional. 